\title{
Optimizing the concentration of 2,4,6-trimethylbenzoyldiphenylphosphine oxide initiator in composite resins in relation to monomer conversion
}

\author{
Vesna MILETIC ${ }^{1}$ and Ario SANTINI ${ }^{2}$ \\ ${ }^{1}$ University of Belgrade, School of Dental Medicine, Department of Restorative Odontology and Endodontics, Rankeova 4, 11000 Belgrade, Serbia \\ ${ }^{2}$ The University of Edinburgh, Edinburgh Postgraduate Dental Institute, Lauriston Place, Edinburgh EH3 9HA, United Kingdom \\ Corresponding author, Ario SANTINI; E-mail: ariosantini@hotmail.com
}

\begin{abstract}
The aim of this study was to optimize the concentration of 2,4,6-trimethylbenzoyldiphenylphosphine oxide (Lucirin ${ }^{\circledR}$ TPO) in unfilled and filled composite resins in relation to the degree of conversion (DC). Increasing concentrations of Lucirin ${ }^{\circledR}$ TPO between $0.05-$ $4.97 \mathrm{wt} \%$ were added to equimolar mixtures of Bis-GMA/TEGDMA. Filled resins contained 75 wt\% fillers. Standardized samples were cured using a polywave LED light-curing unit (bluephase ${ }^{\circledR}$ G2, Ivoclar Vivadent). Increased initiator concentrations increased logarithmically the DC of unfilled and filled resins. The DC of unfilled resins was in the range of $73-91 \%$ at the top and $63-81 \%$ at the bottom surfaces and that of filled resins was in the range of $53-81 \%$ at the top and $47-70 \%$ at the bottom surfaces. The DC in unfilled and filled resins reached a plateau at $1.08 \mathrm{wt} \%$ and $1.50 \mathrm{wt} \%$ Lucirin ${ }^{\circledR} \mathrm{TPO}$, respectively. Fillers significantly reduced conversion but had no effect on the logarithmic relationship between initiator concentration and the DC.
\end{abstract}

Keywords: Lucirin ${ }^{\circledR}$ TPO, Composite, Degree of conversion, Raman, Light curing unit

\section{INTRODUCTION}

Polymerization of dental adhesives and resin-based composites (RBCs) is still generally based on light activation of a camphorquinone (CQ)-tertiary amine system. CQ alone has been shown to have a clinically unacceptable low rate of polymerization and significantly lower final conversion rate compared to the $\mathrm{CQ}$-amine system $^{1)}$. The use of the CQ-amine system is limited by aesthetic requirements due to the yellow, unbleachable, chromophore group in $\mathrm{CQ}$ as well as the by-products of tertiary amines ${ }^{2,3}$. Furthermore, this initiator system has shown leachable ${ }^{4)}$ and toxic potential ${ }^{5}$.

Alternative initiators, such as $\alpha$-diketone phenylpropanedione, acylphosphine oxide derivatives ${ }^{2,6)}$, camphorquinone derivative with an acylphosphine oxide group $^{7)}$ and octyloxy-phenyl-phenyl iodonium hexafluoroantimonate ${ }^{8)}$ have been used in experimental dental resins.

It has been stated that 2,4,6-trimethylbenzoyldiphe nylphosphine oxide (Lucirin ${ }^{\circledR}$ TPO) is already present in some commercial RBCs ${ }^{9)}$. Lucirin ${ }^{\circledR} \mathrm{TPO}$ has been studied as an alternative initiator to the CQ-amine system in adhesive $^{10,11)}$ as well as RBC formulations ${ }^{2,12}$. Unfilled methacrylate mixtures containing Lucirin ${ }^{\circledR}$ TPO showed comparable or higher degrees of conversion (DC) and color stability than $\mathrm{CQ}$-amine and phenylpropanedione containing resins ${ }^{2}$. Lucirin ${ }^{\circledR}$ TPO resulted in higher DC than CQ-amine in composite resins cured with halogen ${ }^{12}$ ) or polywave light-curing units (LCUs) ${ }^{13)}$. In dental adhesives, the use of Lucirin ${ }^{\circledR}$ TPO instead of CQ-amine results in similar DC and mechanical properties when cured with a polywave LED LCU ${ }^{11}$.

A disadvantage of Lucirin ${ }^{\circledR}$ TPO is that its absorption spectrum extends from $380 \mathrm{~nm}$ to about $425 \mathrm{~nm}$ and does not match the $430-490 \mathrm{~nm}$ emission spectra of most monowave LED LCUs ${ }^{14}$. Recently marketed polywave LED LCUs have two emission peaks, one around 467 $\mathrm{nm}$ to cover the absorption spectrum of $\mathrm{CQ}$ and another around $400 \mathrm{~nm}$ to match Lucirin ${ }^{\circledR}$ TPO.

No study could be found on the effect of varying concentrations of Lucirin ${ }^{\circledR}$ TPO on the DC of experimental composite resins. The aim of this study was to optimize the concentration of Lucirin ${ }^{\circledR}$ TPO in unfilled and filled composite resin mixtures for maximum DC in clinically relevant curing conditions. The null hypotheses were that neither different concentrations of the initiator nor the addition of fillers have an effect on the DC.

\section{MATERIAL AND METHODS}

The following materials were used in the study: bisphenol A bis(2-bydroxy-3-methacryloxypropyl)ether (Bis-GMA), triethyleneglycol dimethacrylate(TEGDMA), (Esstech Inc., Essington, PA, USA), Lucirin ${ }^{\circledR}$ TPO and fillers used in Tetric EvoCeram, both supplied by Ivoclar Vivadent (Schaan, Liechtenstein). According to the manufacturer's data, the fillers are a mixture of barium oxide, ytterbium trifluoride and mixed oxides, 40-3000 $\mathrm{nm}$ in size with a mean particle size of $550 \mathrm{~nm}$. All materials were used as received. Bis-GMA and TEGDMA, $1 \mathrm{mmol}$ each, were measured in a dark eppendorf on an analytical balance (Sartorius AG, Goettingen, Germany, $\mathrm{d}=0.01 \mathrm{mg}$ ), and homogenized for $24 \mathrm{~h}$ on a rotator wheel (Stuart ${ }^{\circledR}$ SB3, Bibby Scientific Ltd, Staffordshire, UK). Lucirin $^{\circledR}$ TPO was added in concentrations of 0.00125$0.12 \mathrm{mmol}$ that corresponded to $0.05-4.97 \mathrm{wt} \%$.

Filled resins were prepared as $25 \mathrm{wt} \%$ resin and 75 wt\% fillers. Appropriate amounts of fillers were measured on the same analytical balance and added 
to each resin mixture in small amounts followed by vortexing and centrifuging (Heraeus Pico, DJB Labcare Ltd, Buckinghamshire, UK) until homogenous mixtures were achieved. Prepared filled resins were stirred by hand using a metal spatula immediately before sample preparation.

The absorption spectrum of Lucirin ${ }^{\circledR} \mathrm{TPO}$ in toluene $\left(0.00152 \mathrm{M} \mathrm{l}^{-1}\right)$ was obtained in the range of 380-530 nm using a UV-Vis spectrophotometer (Agilent 8453 UVVisible spectrophotometer, Agilent Technologies UK Limited, Stockport, UK).

Each sample was prepared by filling a plastic mould (Felix, Novi Sad, Serbia), $5 \mathrm{~mm}$ in diameter and $2 \mathrm{~mm}$ thick, placed on a Mylar strip on a microscopic slide. The material was covered by another Mylar strip and light cured for $20 \mathrm{~s}$ using a polywave LED LCU (bluephase ${ }^{\circledR}$ G2, Ivoclar Vivadent, Schaan, Liechtenstein). The tip-to-surface distance of $1 \mathrm{~mm}$ was maintained by a custom-made spacer. The curing parameters, light irradiance, energy and emission peaks were monitored using MARC ${ }^{\text {TM }}$ (BlueLight analytics Inc, Halifax, NS, Canada) which incorporates a spectroradiometer (USB 4000, Ocean Optics, Dunedin, FL). The samples were wet polished with superfine polishing discs (Buehler, Lake Bluff, IL, USA) for $10 \mathrm{~s}$. Three samples per group were prepared for unfilled and six per group for filled resins according to the sample size calculation based on the number of groups and estimated standard deviation values.

Micro-Raman analysis was done within 10 min postcuring with the samples being retained in the moulds. Standard micro-Raman parameters of the spectrometer used in this study (LabRam 300, Horiba JobinYvon, Stanmore, Middlesex, UK) were: $20 \mathrm{~mW}$ HeNe laser with $632.817 \mathrm{~nm}$ wavelength, spatial resolution $\sim 1.5$ $\mu \mathrm{m}$, spectral resolution $\sim 2.5 \mathrm{~cm}^{-1}, \times 100$ magnification.

The DC was calculated according to the following formula:
$\mathrm{DC}=\left(1-\mathrm{R}_{\text {cured }} / \mathrm{R}_{\text {uncured }}\right) * 100$

where $\mathrm{R}$ is the ratio of peak heights at $1639 \mathrm{~cm}^{-1}$ and $1609 \mathrm{~cm}^{-1}$ in cured and uncured material which served as reference. Three point spectra each were taken from the top and bottom surface of each sample.

Statistical analysis was done in Minitab 15 (Minitab Inc., State College, PA, USA). The assumptions required for parametric testing were validated using KolmogorovSmirnov and Bartlett's tests. The differences in DC values were evaluated using a general linear model ANOVA for the factors "concentration" and "surface". Further testing was done using one-way ANOVA with the Bonferroni correction and Tukey's post hoc comparisons for each surface, top or bottom, of unfilled and filled resins. The level of significance was $\alpha=0.05$. Regression analysis was performed to establish the relationship between the initiator concentration and the resultant DC of resins.

\section{RESULTS}

Figure 1 shows the absorption spectrum of Lucirin ${ }^{\circledR}$ TPO and emission spectrum of bluephase ${ }^{\circledR}$ G2. The mean irradiance of the bluephase ${ }^{\circledR}$ G2 LCU was $1208.94 \mathrm{~mW} /$ $\mathrm{cm}^{2}$ and the total energy was $2.33 \mathrm{~J} / \mathrm{cm}^{2}$ and $23.40 \mathrm{~J} / \mathrm{cm}^{2}$ in the $380-420 \mathrm{~nm}$ and $420-540 \mathrm{~nm}$ regions, respectively.

Figures 2 and 3 show plotted DC values against initiator concentrations. $\mathrm{R}^{2}$ values of 0.9552 and 0.9423 for the top surfaces in unfilled and filled resins, respectively, indicated a better logarithmic fit compared to the bottom surfaces. The DC values at the bottom surfaces of unfilled resins showed a better logarithmic fit $\left(\mathrm{R}^{2}=0.8525\right)$ than the filled resins which showed least predictability $\left(\mathrm{R}^{2}=0.7716\right)$.

Statistical analysis is summarized in Tables 1 and 2. In both types of resins very low initiator concentrations showed significantly lower DC values at the top and bottom surfaces compared to higher

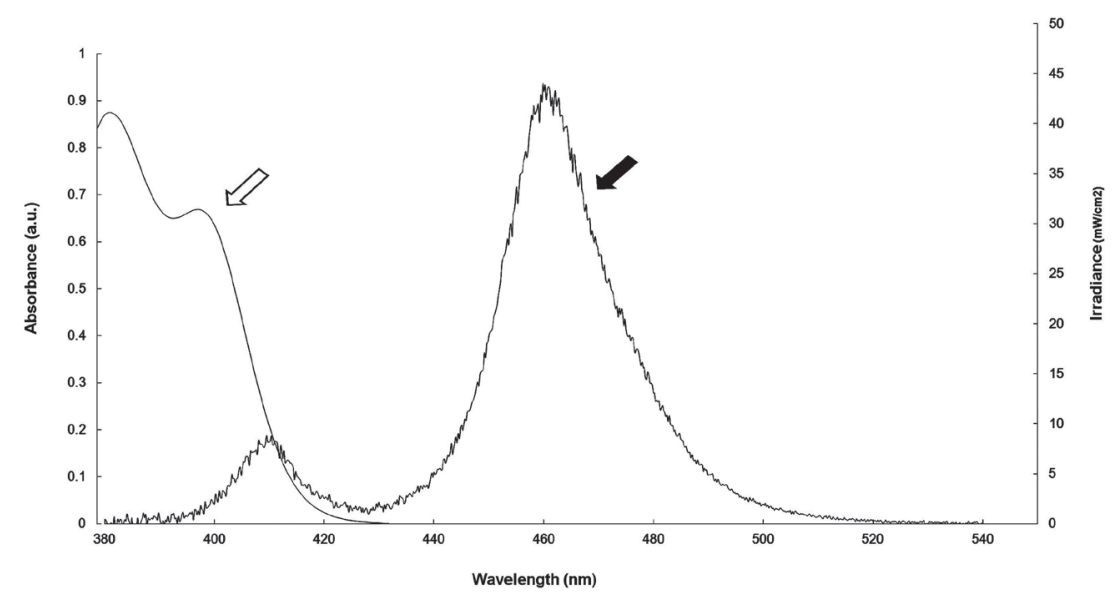

Fig. 1 Absorption spectrum of Lucirin ${ }^{\circledR}$ TPO (white arrow) and emission spectrum of bluephase ${ }^{\circledR}$ G2 light-curing unit (black arrow). 


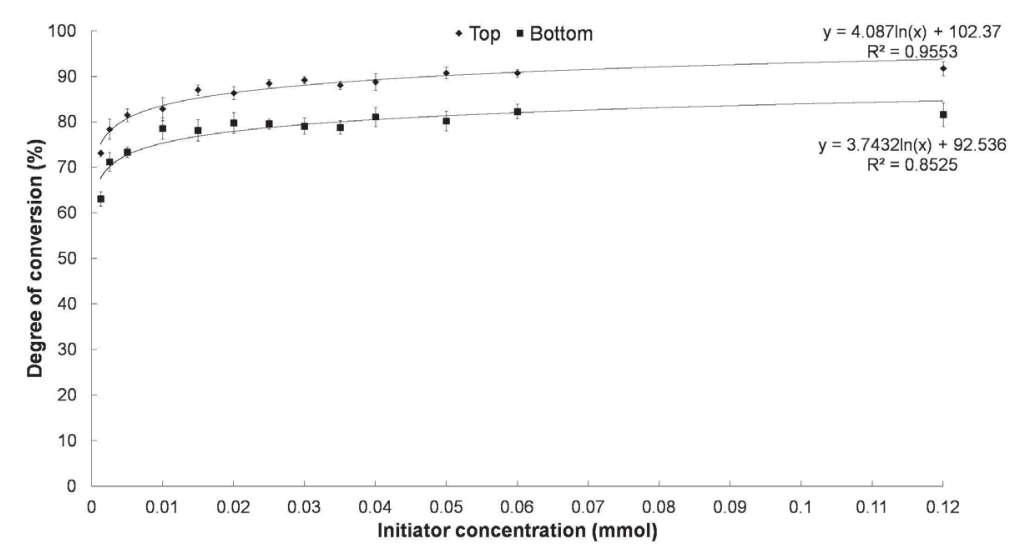

Fig. 2 Mean and standard deviation values of the degree of conversion of unfilled resins plotted against initiator concentrations.

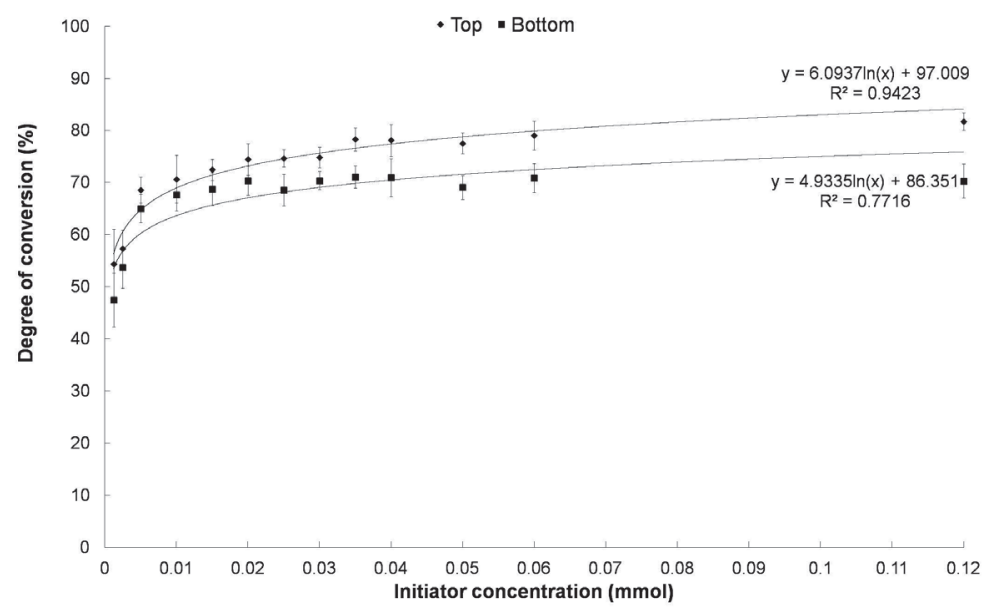

Fig. 3 Mean and standard deviation values of the degree of conversion of filled resins plotted against initiator concentrations.

initiator concentrations. Lucirin ${ }^{\circledR} \mathrm{TPO}$ in excess of 0.43 wt\% resulted in the $\mathrm{DC}$ values that started to level off with very small increase with each subsequent initiator concentration. Unfilled resins containing more than 1.08 wt\% Lucirin ${ }^{\circledR}$ TPO showed similar DC values $(p>0.05)$, except for the top surface of unfilled resin containing the highest concentration of initiator which resulted in the highest $\mathrm{DC}$ values. The addition of fillers reduced the DC by about 10-20\%. There were no statistically significant differences in the DC values between filled resins containing more than $1.50 \mathrm{wt} \%$ Lucirin $^{\circledR}$ TPO $(p>0.05)$.

Figure 4 shows the average DC ratios between bottom and top surfaces and between filled and unfilled resins. In most cases, higher bottom-to-top ratios were observed for filled compared to unfilled resins. Similarly, higher filled/unfilled ratios were found for bottom compared to top surfaces.

\section{DISCUSSION}

Generally, increased concentrations of Lucirin ${ }^{\circledR}$ TPO resulted in higher DC of both unfilled and filled resins. On the other hand, the addition of fillers reduced the DC of the resins irrespective of the amount of Lucirin ${ }^{\circledR}$ TPO. Therefore, both null hypotheses were rejected.

Light irradiance of the polywave bluephase ${ }^{\circledR}$ G2 LCU obtained using MARC ${ }^{\mathrm{TM}}$, corresponded to manufacturer's technical data. Further analysis of light curing parameters revealed that energy of about $2 \mathrm{~J} / \mathrm{cm}^{2}$ was delivered in the range of $380-425 \mathrm{~nm}$. This means that less than $10 \%$ of the total energy of this LCU initiated Lucirin ${ }^{\circledR}$ TPO. On the other hand, previous studies have shown that substantially higher energy is required for sufficient polymerization of RBCs containing a CQ-amine system ${ }^{15-17)}$. The differences in the initiating potential between Lucirin ${ }^{\circledR} \mathrm{TPO}$ and CQ-amine and the 
Table 1 Summary of statistical analysis for unfilled resins: upper and lower 95\% confidence intervals (CI) and statistically significant differences between groups

\begin{tabular}{|c|c|c|c|c|c|}
\hline \multicolumn{2}{|c|}{$\begin{array}{l}\text { Lucirin }^{\circledR} \text { TPO } \\
\text { concentration }\end{array}$} & \multicolumn{2}{|c|}{ Top surface } & \multicolumn{2}{|c|}{ Bottom surface } \\
\hline mmol & wt $\%$ & $95 \%$ CI & $\begin{array}{c}\text { Statistical } \\
\text { significance }\end{array}$ & $95 \% \mathrm{CI}$ & $\begin{array}{c}\text { Statistical } \\
\text { significance }\end{array}$ \\
\hline 0.00125 & 0.05 & $72.5-73.7$ & 1 & $61.9-64.3$ & 1 \\
\hline 0.0025 & 0.11 & $76.7-80.1$ & 2 & $69.6-72.8$ & 2 \\
\hline 0.005 & 0.22 & $80.5-82.5$ & 3 & $72.5-74.2$ & 2 \\
\hline 0.01 & 0.43 & $81.2-84.5$ & 3 & $77.1-80.1$ & 3,4 \\
\hline 0.015 & 0.65 & $86.1-87.9$ & 4,5 & $76.3-79.9$ & 3 \\
\hline 0.02 & 0.86 & $85.2-87.4$ & 4 & $78.0-81.5$ & 3,5 \\
\hline 0.025 & 1.08 & $87.8-89.1$ & $4,6,7$ & $78.7-80.4$ & 3,6 \\
\hline 0.03 & 1.29 & $88.6-89.8$ & $5,6,8,9$ & $77.7-80.5$ & 3,7 \\
\hline 0.035 & 1.50 & $87.3-88.7$ & $4,8,10$ & $77.7-79.9$ & 3,8 \\
\hline 0.04 & 1.71 & $87.3-90.2$ & $5,7,10$ & $79.4-82.7$ & 3,9 \\
\hline 0.05 & 2.13 & $89.8-91.7$ & $7,9,11$ & $78.5-81.8$ & 3,10 \\
\hline 0.06 & 2.55 & $90.0-91.4$ & $7,9,11$ & $81.1-83.5$ & $5,6,7,9,10$ \\
\hline 0.12 & 4.97 & $90.7-92.7$ & 11 & $79.9-83.3$ & $4,5,6,7,8,9,10$ \\
\hline
\end{tabular}

Same numbers indicate no significant difference $(p>0.05)$

Table 2 Summary of statistical analysis for filled resins: upper and lower 95\% confidence intervals (CI) and statistically significant differences between groups

\begin{tabular}{|c|c|c|c|c|c|}
\hline \multirow{2}{*}{\multicolumn{2}{|c|}{$\begin{array}{l}\text { Lucirin }^{\circledR} \text { TPO } \\
\text { concentration }\end{array}$}} & \multicolumn{2}{|c|}{ Top surface } & \multicolumn{2}{|c|}{ Bottom surface } \\
\hline & & $95 \% \mathrm{CI}$ & $\begin{array}{c}\text { Statistical } \\
\text { significance }\end{array}$ & $95 \%$ CI & $\begin{array}{c}\text { Statistical } \\
\text { significance }\end{array}$ \\
\hline 0.00125 & 0.05 & $51.0-57.7$ & 1 & $45.0-50.0$ & 1 \\
\hline 0.0025 & 0.11 & $55.6-59.0$ & 1 & $51.8-55.6$ & 2 \\
\hline 0.005 & 0.22 & $67.3-69.8$ & 2 & $63.7-66.4$ & 3,4 \\
\hline 0.01 & 0.43 & $68.4-72.9$ & 2,3 & $66.1-69.2$ & 4,5 \\
\hline 0.015 & 0.65 & $71.5-73.5$ & 3 & $67.2-70.3$ & 4,5 \\
\hline 0.02 & 0.86 & $73.0-76.0$ & 3 & $69.0-71.7$ & 5 \\
\hline 0.025 & 1.08 & $73.7-75.7$ & 3,4 & $66.5-70.6$ & 5 \\
\hline 0.03 & 1.29 & $73.9-75.7$ & 3,5 & $69.6-71.1$ & 5 \\
\hline 0.035 & 1.50 & $77.2-79.4$ & 5,6 & $70.0-72.1$ & 5 \\
\hline 0.04 & 1.71 & $76.5-79.6$ & $4,5,7$ & $69.2-72.8$ & 5 \\
\hline 0.05 & 2.13 & $76.5-78.5$ & $4,5,8$ & $67.9-70.2$ & 5 \\
\hline 0.06 & 2.55 & $77.7-80.4$ & $6,7,8$ & $69.5-72.2$ & 5 \\
\hline 0.12 & 4.97 & $80.9-82.5$ & 6,7 & $68.7-71.8$ & 5 \\
\hline
\end{tabular}

Same numbers indicate no significant difference $(p>0.05)$ 


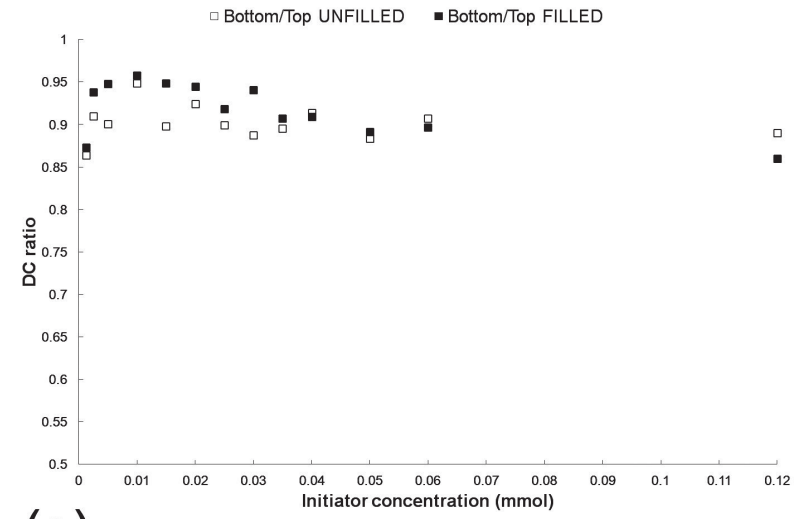

(a)

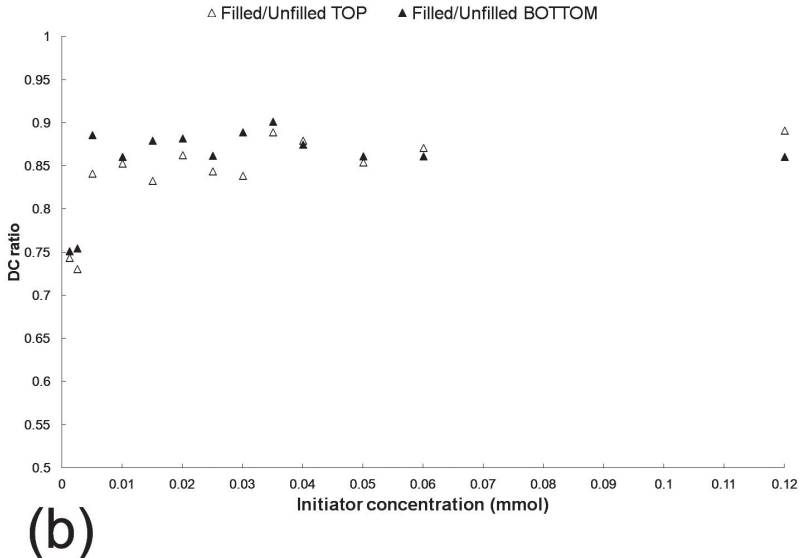

Fig. 4 (a) Bottom-to-top ratio of the degree of conversion values for unfilled and filled resins; (b) The ratio of the degree of conversion values between filled and unfilled resins containing the same concentration of Lucirin ${ }^{\circledR}$ TPO.

lack of data for polywave LED LCUs justify the need to systematically assess the effect of varying concentrations of Lucirin ${ }^{\circledR}$ TPO on the DC of unfilled and filled resins cured with such LCUs.

In the present study, a wide range of initiator concentrations was used, from $0.05 \mathrm{wt} \%$ to $4.97 \mathrm{wt} \%$ Lucirin $^{\circledR}$ TPO, in an equimolar Bis-GMA/TEGDMA mixture. Concentrations between $0.037 \mathrm{wt} \%$ and 1.5 wt\% Lucirin ${ }^{\circledR}$ TPO were used in previous studies which evaluated various properties of resins containing different initiators ${ }^{2,12,18,19)}$. Since manufacturers state that initiator concentration in their materials is up to $1 \mathrm{wt} \%$, small increments of about $0.2 \mathrm{wt} \%$ Lucirin $^{\circledR} \mathrm{TPO}$ were tested in this range.

Samples were polished to remove the oxygen inhibition layer and obtain DC values that closely match the bulk polymer. Wet polishing was applied since it has been shown to have no effect on DC value $^{20)}$. Micro-Raman analysis was done within $10 \mathrm{~min}$ post-polymerization since studies on polymerization kinetics of various resin models and RBCs have shown a plateau in conversion within minutes of the start of polymerization $^{21-23)}$.

The present results have shown a logarithmic relationship between the amount of Lucirin ${ }^{\circledR}$ TPO and the resultant DC for both unfilled and filled resins. The greatest increase in the DC values occurred between the two groups containing the smallest amount of initiators. The increase in the DC values approached plateau for initiator concentrations exceeding $1.08 \mathrm{wt} \%$ in unfilled and $1.5 \mathrm{wt} \%$ in filled resins. Small rise in the DC beyond these concentrations had no statistically significant effect on monomer to polymer conversion and is not expected to have a significant effect on material properties. On the other hand, initiator concentrations of $0.22-0.43$ wt\% seem to be the lower cut-off points for acceptable DC values. Further studies are necessary to relate monomer conversion to various material properties as a function of Lucirin ${ }^{\circledR}$ TPO concentration. The present study may serve as an indicator of relevant initiator concentrations with regard to changes in monomer to polymer conversion.

Addition of fillers significantly reduced the DC irrespective of initiator concentrations. This is in agreement with a study by Leprince et $a l .{ }^{12)}$ who reported the same finding for resins initiated by CQ-amine or Lucirin ${ }^{\circledR}$ TPO. Previous studies have also reported lower DC values with increased filler loading ${ }^{24)}$ and particle $\operatorname{siz}^{25)}$. Present findings have shown that fillers did not affect the logarithmic relationship between the initiator concentration and the DC. This suggests that the free radical polymerization occurs in much the same way across the entire range of tested initiator concentrations irrespective of the presence of fillers. Possible filler effect on light penetration and restricted mobility within the growing polymer may be the reasons why higher initiator concentrations in the filled resins were required to reach the conversion plateau compared to unfilled resins.

A previous study has reported that Lucirin ${ }^{\circledR}$ TPO results in lower depth of cure in unfilled and filled resins compared to the equimolar concentration of $\mathrm{CQ}$-amine. This was attributed to a higher molar absorptivity of Lucirin ${ }^{\circledR}$ TPO which may lead to reduced penetration of light with depth ${ }^{12)}$. In the present study, higher bottomto-top ratios in filled resins indicate less difference in DC values across sample thickness compared to unfilled resins. Once fillers are added monomer conversion becomes restricted even in the surface layers closest to the light source. Similarly, higher DC ratios for bottom than top surfaces in filled and unfilled resin containing the same initiator concentrations indicate less difference in DC values in unfilled and filled resins with depth. The decrease in monomer conversion with depth is greater in unfilled resins probably because of higher consumption of photons of light by the initiator in the absence of fillers which reduces Lucirin ${ }^{\circledR}$ TPO initiation with depth.

The consensus DC values for most experimental and commercial RBCs are in the range of $40-75 \%{ }^{20,26-29)}$. 
The present results are in agreement with these previously reported DC values for RBCs initiated by $\mathrm{CQ}$ amine systems. Lucirin ${ }^{\circledR}$ TPO concentration in excess of $0.86 \mathrm{wt} \%$ resulted in $74 \%$ or higher DC in the filled resins. Moreover, as little as 0.22 wt\% Lucirin ${ }^{\circledR}$ TPO resulted in $68 \%$ DC which was still higher than many of the previously tested RBCs. It should be noted that such high DC values were obtained with only about 2 $\mathrm{J} / \mathrm{cm}^{2}$ of delivered light energy in the absorption region of Lucirin ${ }^{\circledR}$ TPO. A high reactivity of Lucirin ${ }^{\circledR}$ TPO when initiated with a polywave LED LCU may be due to its higher molar extinction coefficient, polymerization quantum yield and, thus, polymerization efficiency than $\mathrm{CQ}$-amine in the case of matching emission spectra of the LCUs and absorption spectra of initiators ${ }^{19,30)}$.

\section{CONCLUSION}

Lucirin $^{\circledR}$ TPO has shown a high reactivity upon irradiation with the polywave bluephase ${ }^{\circledR}$ G2 LED LCU whose additional emission peak around $400 \mathrm{~nm}$ matches the absorption spectrum of this initiator. Increased concentrations of Lucirin ${ }^{\circledR}$ TPO increased the DC logarithmically in an equimolar Bis-GMA/TEGDMA mixture. Monomer to polymer conversion reached plateau values at $1.08 \mathrm{wt} \%$ and $1.5 \mathrm{wt} \%$ of Lucirin ${ }^{\circledR}$ TPO in unfilled and filled resins, respectively. High conversion with depth and in the presence of fillers in clinically relevant material thickness was maintained when Lucirin ${ }^{\circledR}$ TPO was in excess of 0.22 wt\%. Fillers significantly reduced conversion but had no effect on the relationship between initiator concentration and the DC.

\section{ACKNOWLEDGMENTS}

The authors wish to express their gratitude to Professors Mark Bradley and Colin Pulham of the School of Chemistry, The University of Edinburgh, for unrestricted use of their laboratories and to Dr Michael D. Swift for his helpful comments. The authors thank Ivoclar Vivadent, Schaan, Liechtenstein for providing Lucirin $^{\circledR}$ TPO, fillers and bluephase ${ }^{\circledR}$ G2 light-curing units and Esstech Inc., Essington, PA, USA for providing Bis-GMA and TEGDMA.

Dr. Miletic's accommodation, subsistence and travel during her stay at the University of Edinburgh were funded by the IADR Toshio Nakao Fellowship and Research grant ON172007 from the Ministry of Education and Science, Republic of Serbia.

\section{REFERENCES}

1) Schroeder WF, Vallo CI. Effect of different photoinitiator systems on conversion profiles of a model unfilled light-cured resin. Dent Mater 2007; 23: 1313-1321.

2) Arikawa H, Takahashi H, Kanie T, Ban S. Effect of various visible light photoinitiators on the polymerization and color of light-activated resins. Dent Mater J 2009; 28: 454-460.

3) Cramer NB, Stansbury JW, Bowman CN. Recent advances and developments in composite dental restorative materials. J Dent Res 2011; 90: 402-416.
4) Michelsen VB, Lygre H, Skalevik R, Tveit AB, Solheim E. Identification of organic eluates from four polymer-based dental filling materials. Eur J Oral Sci 2003; 111: 263-271.

5) Masuki K, Nomura Y, Bhawal UK, Sawajiri M, Hirata I, Nahara Y, Okazaki M. Apoptotic and necrotic influence of dental resin polymerization initiators in human gingival fibroblast cultures. Dent Mater J 2007; 26: 861-869.

6) Ikemura K, Endo T. A review of the development of radical photopolymerization initiators used for designing light-curing dental adhesives and resin composites. Dent Mater J 2010; 29: 481-501.

7) Ikemura K, Ichizawa K, Jogetsu Y, Endo T. Synthesis of a novel camphorquinone derivative having acylphosphine oxide group, characterization by UV-VIS spectroscopy and evaluation of photopolymerization performance. Dent Mater J 2010; 29: 122-131.

8) Shin DH, Rawls HR. Degree of conversion and color stability of the light curing resin with new photoinitiator systems. Dent Mater 2009; 25: 1030-1038.

9) Palin WM, Senyilmaz DP, Marquis PM, Shortall AC. Cure width potential for MOD resin composite molar restorations. Dent Mater 2008; 24: 1083-1094.

10) Cadenaro M, Antoniolli F, Codan B, Agee K, Tay FR, Dorigo Ede S, Pashley DH, Breschi L. Influence of different initiators on the degree of conversion of experimental adhesive blends in relation to their hydrophilicity and solvent content. Dent Mater 2010; 26: 288-294.

11) Ilie N, Hickel R. Can CQ be completely replaced by alternative initiators in dental adhesives? Dent Mater J 2008; 27: 221228.

12) Leprince JG, Hadis M, Shortall AC, Ferracane JL, Devaux J, Leloup G, Palin WM. Photoinitiator type and applicability of exposure reciprocity law in filled and unfilled photoactive resins. Dent Mater 2011; 27: 157-164.

13) Miletic V, Santini A. Micro-Raman spectroscopic analysis of the degree of conversion of composite resins containing different initiators cured by polywave or monowave LED units. J Dent 2012; 40: 106-113.

14) Santini A. Current status of visible light activation units and the curing of light-activated resin-based composite materials. Dent Update 2010; 37: 214-216, 218-220, 223-227.

15) Davidson CL, de Gee AJ. Light-curing units, polymerization, and clinical implications. J Adhes Dent 2000; 2: 167-173.

16) Emami N, Soderholm KJ. How light irradiance and curing time affect monomer conversion in light-cured resin composites. Eur J Oral Sci 2003; 111: 536-542.

17) Halvorson RH, Erickson RL, Davidson CL. Energy dependent polymerization of resin-based composite. Dent Mater 2002; 18: 463-469.

18) Cadenaro M, Breschi L, Antoniolli F, Navarra CO, Mazzoni A, Tay FR, Di Lenarda R, Pashley DH. Degree of conversion of resin blends in relation to ethanol content and hydrophilicity. Dent Mater 2008; 24: 1194-1200.

19) Neumann MG, Miranda WG Jr., Schmitt CC, Rueggeberg FA, Correa IC. Molar extinction coefficients and the photon absorption efficiency of dental photoinitiators and light curing units. J Dent 2005; 33: 525-532.

20) Miletic VJ, Santini A. Remaining unreacted methacrylate groups in resin-based composite with respect to sample preparation and storing conditions using micro-Raman spectroscopy. J Biomed Mater Res B Appl Biomater 2008; 87: 468-474.

21) Cramer NB, Couch CL, Schreck KM, Boulden JE, Wydra R, Stansbury JW, Bowman CN. Properties of methacrylatethiol-ene formulations as dental restorative materials. Dent Mater 2010; 26: 799-806.

22) Cramer NB, Couch CL, Schreck KM, Carioscia JA, Boulden JE, Stansbury JW, Bowman CN. Investigation of thiol-ene and thiol-ene-methacrylate based resins as dental restorative materials. Dent Mater 2010; 26: 21-28. 
23) Daronch M, Rueggeberg FA, De Goes MF, Giudici R. Polymerization kinetics of pre-heated composite. J Dent Res 2006; 85: 38-43.

24) Halvorson RH, Erickson RL, Davidson CL. The effect of filler and silane content on conversion of resin-based composite. Dent Mater 2003; 19: 327-333.

25) Karabela MM, Sideridou ID. Synthesis and study of properties of dental resin composites with different nanosilica particles size. Dent Mater 2011; 27: 825-835.

26) Atai M, Motevasselian F. Temperature rise and degree of photopolymerization conversion of nanocomposites and conventional dental composites. Clin Oral Investig 2009; 13: 309-316.
27) Beun S, Glorieux T, Devaux J, Vreven J, Leloup G. Characterization of nanofilled compared to universal and microfilled composites. Dent Mater 2007; 23: 51-59.

28) Ilie N, Hickel R. Silorane-based dental composite: behavior and abilities. Dent Mater J 2006; 25: 445-454.

29) Lopez-Suevos F, Dickens SH. Degree of cure and fracture properties of experimental acid-resin modified composites under wet and dry conditions. Dent Mater 2008; 24: 778-785.

30) Neumann MG, Schmitt CC, Ferreira GC, Correa IC. The initiating radical yields and the efficiency of polymerization for various dental photoinitiators excited by different light curing units. Dent Mater 2006; 22: 576-584. 